\title{
Materials Challenges in Advanced Coal Conversion Technologies
}

\author{
Cynthia A. Powell (National Energy Technology Laboratory, USA) \\ Bryan D. Morreale (National Energy Technology Laboratory, USA)
}

\begin{abstract}
Coal is a critical component in the international energy portfolio, used extensively for electricity generation. Coal is also readily converted to liquid fuels and/or hydrogen for the transportation industry. However, energy extracted from coal comes at a large environmental price: coal combustion can produce large quantities of ash and $\mathrm{CO}_{2}$, as well as other pollutants. Advanced technologies can increase the efficiencies and decrease the emissions associated with burning coal and provide an opportunity for $\mathrm{CO}_{2}$ capture and sequestration. However, these advanced technologies increase the severity of plant operating conditions and thus require improved materials that can stand up to the harsh operating environments. The materials challenges offered by advanced coal conversion technologies must be solved in order to make burning coal an economically and environmentally sound choice for producing energy.
\end{abstract}

\section{Introduction}

Coal fueled the Industrial Revolution, and it will continue to play a significant role in fueling world energy needs through the 21 st century. With recoverable reserves available in approximately 70 countries around the world (Figure 1), coal is an abundant, equal-opportunity fuel, particularly for developing countries. World Coal Institute ${ }^{1}$ projections indicate that identified coal reserves are sufficient to last 150 years at current production levels, as compared to 41 and 65 years for proven oil and natural gas reserves, respectively. In addition, coal is a familiar energy source, providing $25 \%$ of global energy needs and generating $40 \%$ of the world's electricity. Finally, coal is relatively inexpensive compared to other fossil fuels; at a price of approximately \$1-2 per million Btu, the cost of coal is approximately one-sixth that of oil or natural gas. ${ }^{2}$ As a result of this combination of abundance and low cost, coal can be expected to continue to play a major and necessary role in the energy mix, as the worldwide demand for affordable energy continues to grow. Indeed, over the next 30 years, it is estimated that global energy demand will increase by almost $60 \%$. The

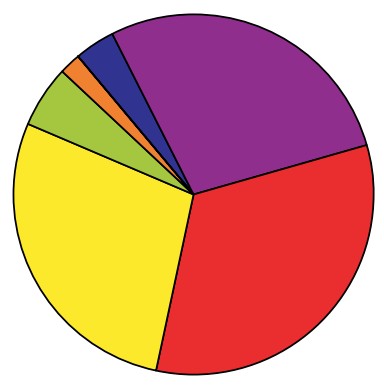

- Western Europe 36,489

- Eastern Europe \& Former USSR 279,778

- Asia Pacific 327,264

- North America 279,506

- Africa 55,486

- South \& Central America 21,928

- Middle East 462

Figure 1. Identified world coal reserves as of 2005 plotted as percentages of the world total. Numbers in legend represent the quantity of recoverable coal available in each region, in million short tons. Source: Reference 3.
United States Department of Energy's Energy Information Administration (EIA) projects that, even with significant increases in the use of alternative energy sources by the U.S. public, 145 gigawatts (GW) of new coal-fired power plant capacity will be needed by $2030 .^{3}$ This is equivalent to approximately 290 new $500 \mathrm{MW}$ power plants in the United States alone. Worldwide, coal consumption is predicted to increase by an average of 2.5\% a year between 2003 and 2030 (Figure 2). The biggest increase in demand is predicted for China, where coal usage will increase by an average of $3.5 \%$ a year, requiring an additional $500 \mathrm{GW}$ of coal-fired capacity for that country by $2030 .^{3}$

However, coal faces significant environmental challenges, both in its mining and in its conversion to energy. A relatively higher carbon-to-hydrogen ratio, combined with the relatively low efficiencies of today's combustion technologies, means

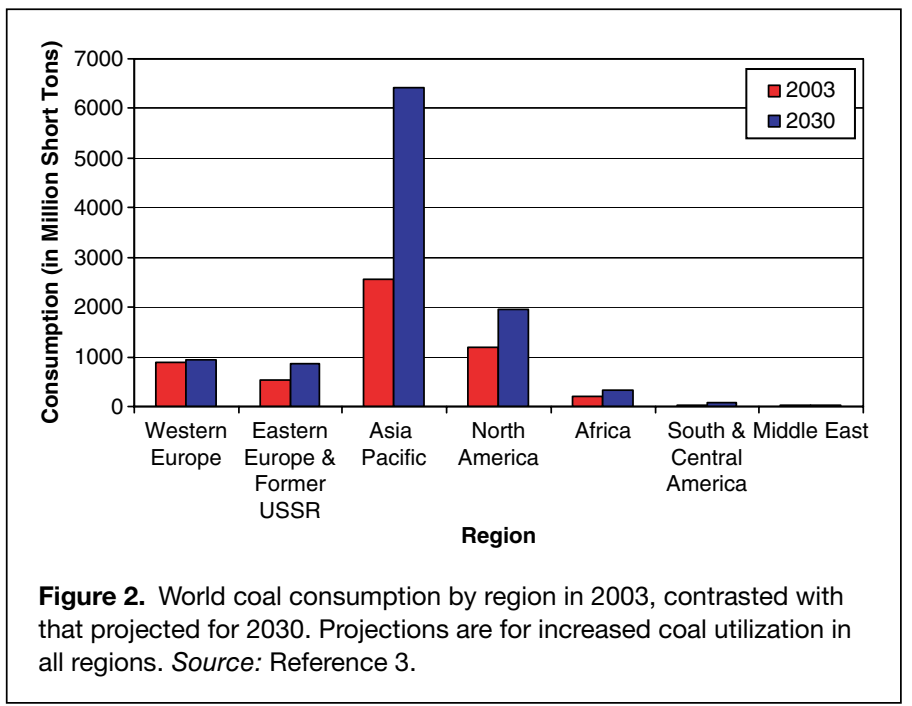


that coal combustion results in higher $\mathrm{CO}_{2}$ emissions per unit heat output than either oil or natural gas. In addition, coal contains a number of inorganic impurities, and its combustion results in the emission of the "criteria pollutants" sulfur dioxide $\left(\mathrm{SO}_{2}\right)$, nitrogen oxides (known collectively as $\mathrm{NO}_{x}$ ), and particulates, as well as mercury. (Criteria pollutants are those regulated by the U.S. Environmental Protection Agency on the basis of human-health-based and/or environmentally based criteria.) Both the specific impurities present in a coal feedstock and their quantities depend on the type of coal and where it is mined, but at least $10 \mathrm{wt} \%$ of any coal is some combination of volatile and noncombustible inorganic components, present primarily in the form of minerals. Some coals consist of $50 \mathrm{wt} \%$, or more, of these non-carbon-based constituents. As a result, any viable coal combustion technology must be able to accommodate the presence of these impurities at elevated temperatures and to remove them from the plant waste stream to levels mandated by local environmental regulations. Good environmental stewardship would seek complete removal and benign sequestration of all pollutants wherever possible in the conversion of this necessary fuel to energy.

Technology advancement to address the world's growing demand for clean and affordable energy will require simultaneous advances in materials science and technology in order to meet the performance demands of new power systems. This is particularly true for coal-based technologies, where the drive for increased efficiencies and reduced environmental impactthe drive to extract as much energy as possible from every ton of coal - calls for the use of increased system operating temperatures and pressures, as well as the ability to perform effectively in increasingly aggressive environments. The addition of alternative feedstocks, such as the combustion of coal and biomass to produce electricity and/or liquid fuels, can also place a huge stress on the materials of construction, to the point where the development of new materials with improved performance characteristics and/or new materials protection strategies are warranted. Each of the evolving clean coal technologies must address specific materials challenges in order to achieve widespread commercialization.

\section{Clean Coal Technologies}

Since the mid-1980s, a worldwide push to reduce the environmental impact of coal's conversion to energy has resulted in the advancement of a group of technologies known collectively as clean coal technologies (CCTs). Designed with the combined goals of minimizing emissions and maximizing energy efficiency for each ton of coal processed, the suite of CCTs in development today comprises advanced pollution controls for new and existing power plants, including $\mathrm{CO}_{2}$ capture and sequestration; advanced combustion technologies; and gasification-based systems. Another goal for these systems is fuel flexibility, allowing for the use of a range of different types of coals, or combinations of coal and other opportunity fuels such as petroleum coke or biomass, without impacting plant performance. Beyond electricity generation, coal gasification systems are also being designed for product flexibility, offering the option of producing liquid fuels and/or hydrogen from coal while minimizing impact on the environment

\section{Advanced Combustion Technologies}

Pulverized coal combustion (PCC), in which finely divided coal particles are combusted in air in a boiler to create steam that is passed through a steam turbine to generate electricity, accounts for over $90 \%$ of coal-fired capacity worldwide (Figure 3). Modern PCC technology is well developed, and today's subcritical coal-fired power plant, operating at a steam temperature of $540^{\circ} \mathrm{C}$ and a steam pressure of $16.5 \mathrm{MPa}$, has a thermal efficiency of approximately $35 \%$. (All thermal efficiencies are reported in terms of higher heating value, or HHV, which takes into account the latent heat of vaporization of water in the combustion of coal.) However, more energy extracted per unit coal means an increase in power plant output and a relative decrease in emissions, and thus, advanced combustion technologies seek to maximize the thermal efficiency of the power plant through increases in steam temperatures and/or pressures above the critical point. Generally, supercritical (SC) power plants are those operating with a steam pressure of $22 \mathrm{MPa}$ or higher, whereas ultrasupercritical (USC) power plants operate with steam conditions greater than $24 \mathrm{MPa}$ and $593^{\circ} \mathrm{C}$. Commercial SC combustion plants, operating at $540-566^{\circ} \mathrm{C}$ and $25 \mathrm{MPa}$, and commercial USC combustion plants, operating at $580-620^{\circ} \mathrm{C}$ and $27-28.5 \mathrm{MPa}$, report efficiencies of up to $41 \%$ and $46 \%$, respectively. Additional increases in thermal efficiencies are being sought through additional increases in steam temperatures and pressures, but these will require further advances in materials technology to be realized at a commercial scale. In the United States, the Department of Energy (DOE) is sponsoring research aimed at maximizing thermal efficiency from coal generation, which, for coal combustion, will require USC steam temperatures and pressures as high as $760^{\circ} \mathrm{C}$ and $37.9 \mathrm{MPa}$. In Europe, the Thermie program is focused on USC steam conditions of $720^{\circ} \mathrm{C}$ and $35 \mathrm{MPa}$, and research in Asia has similar goals.

The materials technology required to construct USC plants with steam temperatures up to $625^{\circ} \mathrm{C}$ and pressures up to $34 \mathrm{MPa}$ is largely available today in the form of commercial steels. ${ }^{4}$ However, increasing steam temperatures to $700^{\circ} \mathrm{C}$ will require higher strength ferritic steels for waterwalls, and higher strength austenitic steels and nickel-based superalloys for the pressure parts that are exposed to the highest steam temperatures (Figure 4). In the steam turbine, the high-pressure/intermediate-pressure rotors, rotating blades, bolting, and inner cylinder are exposed to the highest temperatures and will likely need to be constructed from superalloys. Further increases in steam temperature to meet DOE targets will move beyond the capabilities of iron-based alloys to nickel-based superalloys for most components. To achieve the required long-term creep strength and fatigue resistance, these materials must remain stable at the microstructural level for more than $40,000 \mathrm{~h}$ of operation, at metal temperatures that can be as high as $50^{\circ} \mathrm{C}$ above the steam temperature in some components. The coefficients of thermal expansion (expansion of material with increas-

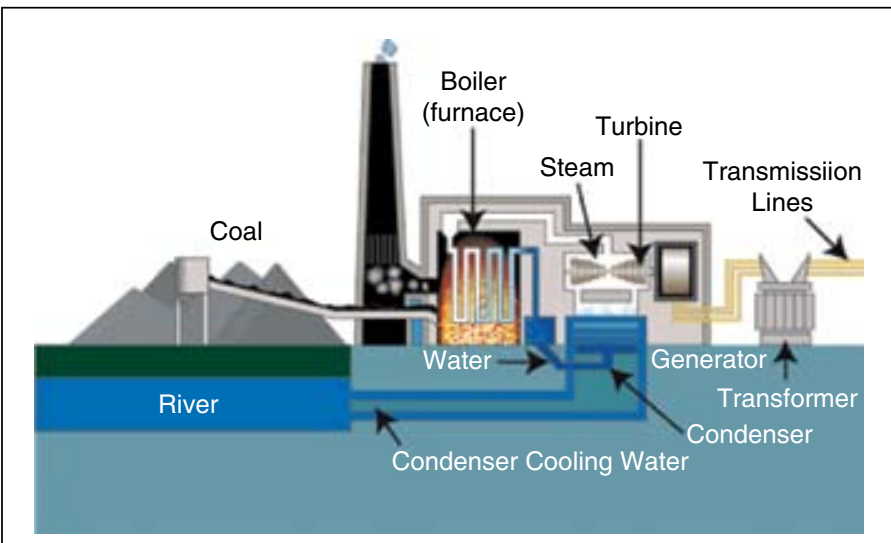

Figure 3. General schematic of a coal combustion plant for generating electricity. Source: Tennessee Valley Authority. 


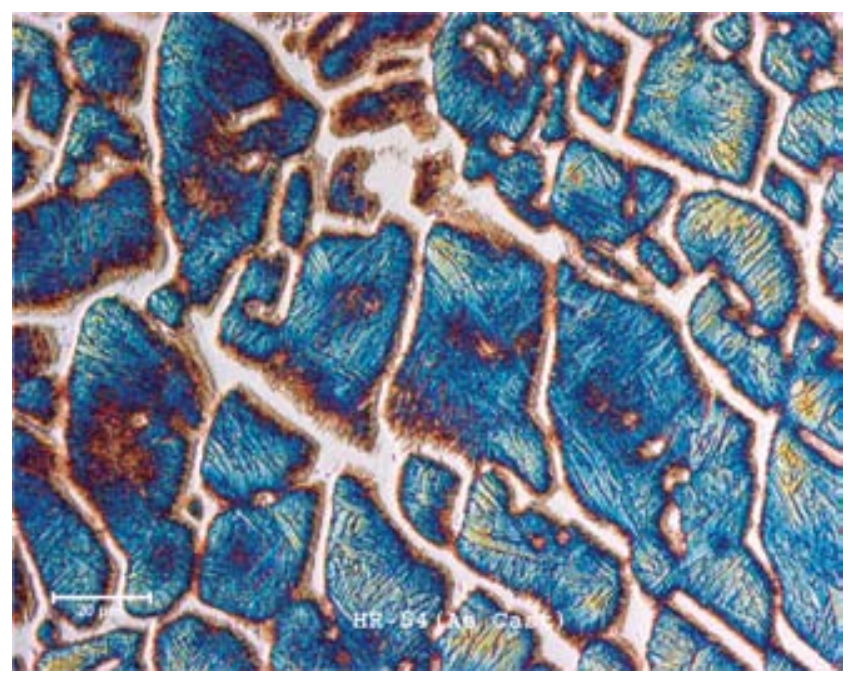

Figure 4. Microstructures of alloys such as this $9 \% \mathrm{Cr}$ stainless steel being developed for next-generation combustion systems will have to be stable at service conditions for up to $40,000 \mathrm{~h}$. (Image courtesy of O. Dogan and P. Danielson of the U.S. National Energy Technology Laboratory.)

ing temperature) must be compatible in those components that are joined with other components, such as the turbine rotors and blades. In addition, the alloys must be resistant to sulfide and chloride attack on the fire side (i.e., inside the boiler, where the coal is combusted) and to oxidation on the steam side (i.e., inside steam piping and within the steam turbine). For many alloys, a chemistry and microstructure optimized for creep resistance are not optimum for required environmental resistance, so effective coating and/or cladding strategies will also have to be considered. Beyond performance, fabricability and weldability must also be designed into the materials being developed. In all cases, because of the very large volume of materials required to construct a power plant, reliability must be obtained at an affordable cost.

Combusting coal in oxygen, as opposed to air, can lead to a significant reduction in $\mathrm{NO}_{x}$ emissions and also simplify $\mathrm{CO}_{2}$ capture for sequestration, so combined with USC technology, it can significantly reduce the environmental impact of PCC plants. Currently, no commercial-scale oxy-fired PCC plants are in operation, although several such new plant constructions were announced recently in the United States. Existing PCC plants could also be retrofitted with oxy-fuel burners, thereby providing a carbon capture option for the existing power fleet. However, with no oxy-fired retrofit boilers currently in operation, there is no experience in how the resulting change in operating environment will impact the boiler materials of construction or the operation of the plant as a whole.

Perhaps the single greatest materials challenge associated with oxy-fuel combustion is in the production of oxygen. Oxygen produced by cryogenic air separation methods can be prohibitively expensive for this application, and a reliable, affordable alternative method for producing oxygen is needed for this as well as other advanced coal combustion technologies. Research is currently focused on developing ion-transport membranes, operating at $800-900^{\circ} \mathrm{C}$, to produce oxygen from compressed air. Ceramic membranes, consisting of proton-conducting perovskites, have the potential to produce highly pure oxygen, but brittleness, sealing difficulties, and relatively low permeabilities have prevented their widespread application to date. Mixed-matrix membranes, utilizing a polymer base coupled with a material that can increase the solubility or diffusivity properties of the composite, such as carbon nanotubes or metal-organic frameworks, are also being investigated. Mixedmatrix membranes are generally classified as being highly permeable, but they suffer from poor selectivity. Regardless of the material selected, the goal is to produce reliable membrane systems that are capable of producing up to 5,000 tons per day of oxygen, although the technology is not expected to be viable before 2015 .

Beyond oxygen production, the materials challenges associated with oxy-fuel combustion are similar to those for USC combustion, except that burning coal with oxygen will increase the radiant component of the flame and, as a result, will increase metal temperatures inside the boiler. However, because an oxyfired boiler has not yet been designed and built, the actual metal temperatures are to be determined. Retrofit oxy-fired systems will likely be designed to match the heat-transfer characteristics of the original boiler, so increased metal temperatures should not be an issue in such cases. In addition to increased temperatures of operation, the relative corrosivity of the fire-side environment will change in oxy-fired systems, and the environmental resistance of the materials of construction will have to be confirmed, or protection strategies developed, to ensure system reliability.

Fluidized-bed combustion (FBC) is another of the advanced combustion technologies that has evolved from efforts to develop an environmentally friendly combustion process that does not require external emission controls. ${ }^{5} \mathrm{FBC}$ systems burn coal, and other carbon-containing feedstocks, in a bed of heated particles suspended in flowing air. The fluidizing action promotes more complete coal combustion at lower flame temperatures, between $760^{\circ} \mathrm{C}$ and $925^{\circ} \mathrm{C}$, which greatly reduces $\mathrm{NO}_{x}$ emissions (nitrogen oxides are typically formed at temperatures approaching $1370^{\circ} \mathrm{C}$ ). In addition, the particle bed includes a sulfur-absorbing sorbent such as limestone or dolomite, which can reduce $\mathrm{SO}_{2}$ emissions by more than $95 \%$. As a result, $\mathrm{FBC}$ systems can meet most environmental standards for $\mathrm{SO}_{2}$ and $\mathrm{NO}_{x}$, without the need for post-combustion pollution controls. Atmospheric-pressure FBCs are available in either a bubbling FBC or circulating FBC configuration, with a power-generating efficiency similar to that of a standard PCC plant. Popular primarily because of its fuel flexibility - an FBC can burn any carbon-containing material, from low-rank coals to municipal waste-and environmental performance, there are now more than $400 \mathrm{FBC}$ units operating worldwide.

A second type of FBC system, the pressurized fluidized-bed combustion (PFBC) system, operates at elevated pressures to produce a gas stream that can drive a gas turbine. However, this technology has yet to find widespread market acceptance.

Materials challenges inherent to FBC systems depend primarily on the type of feedstock utilized, and FBCs sometimes experience excessive materials wastage through corrosion and wear. Combustion of biofuels can result in the formation of alkaline sulfates and chlorides at the tube surfaces, resulting in an accelerated corrosion-erosion of the tube walls. In PFBC systems, product gas streams require removal of fly ash particulate by a series of candle filters before entering the turbine, and filter reliability can be an issue. Ceramic-matrix composites and iron aluminides appear to have sufficient corrosion resistance for this application, although mechanical reliability is still an ongoing issue.

Post-combustion $\mathrm{CO}_{2}$ capture for subsequent sequestration is a challenge for existing coal combustion plants without oxyfuel firing, because it requires the separation of dilute concen- 
trations of $\mathrm{CO}_{2}(13-15 \mathrm{vol} \%$ in a typical coal plant) from the low-pressure flue gas stream. Amine absorbents are currently commercially available that can remove as much of $90 \%$ of the $\mathrm{CO}_{2}$ from the flue gas; however, regeneration of the solvents is an energy-intensive process, resulting in a decrease in plant electricity output of approximately $15 \%$. In addition, amine solvents degrade in the presence of other trace impurities in the flue gas, such as particulates, $\mathrm{SO}_{x}$, and $\mathrm{NO}_{x}$. New absorbent materials and processes that can more effectively and efficiently remove $\mathrm{CO}_{2}$ from the flue gas of conventional coal combustion plants will be needed if $\mathrm{CO}_{2}$ sequestration is to become a reality for the existing coal combustion fleet.

\section{Gasification Technologies}

The gasification process reacts a carbon-containing material, such as coal, with steam and controlled amounts of air or oxygen at high pressures and temperatures to form a synthesis gas composed primarily of carbon monoxide and hydrogen. ${ }^{6}$ Synthesis gas, or syngas, can then be used as a fuel to generate electricity and/or steam, or it can be used as a basic chemical building block for the formation of a variety of liquid fuels or other chemical products (Figure 5). The gasification of coal is not a new technology: "Town gas" (another name for syngas) was widely used in North America and Europe until it was replaced in the 1950 s by natural gas, and Germany used this process to produce substantial amounts of liquid fuels during World War II. However, the technology's fuel and product flexibility, combined with its relatively lower emissions of criteria pollutants compared to advanced combustion technologies and the relatively straightforward extraction of $\mathrm{CO}_{2}$ from the syngas for subsequent sequestration, have brought renewed interest in gasification in recent years.

When the syngas produced by gasification is employed to generate electricity, it is typically used as the fuel in an integrated gasification combined-cycle (IGCC) power generation configuration. In this case, cleaned synthesis gas is combusted in a gas turbine to produce electricity, and the waste heat is used in a combined cycle to turn a steam turbine to generate additional electricity. IGCC systems today (over $1500 \mathrm{MW}$ of coalfired IGCC is currently in operation) can achieve thermal efficiencies of better than $40 \%$, and with improvements in turbine technology, IGCC systems are theoretically capable of better than $50 \%$ efficiency. Synthesis gas produced by coal gasification can also be used to produce hydrogen and liquid fuels, as described in subsequent sections.

Materials challenges associated with gasification involve the reliability of the gasifier itself, as well as the separations technology for oxygen production and synthesis gas processing. ${ }^{7}$ The gasifier, which acts as a containment vessel for the gasification reaction, can operate in either dry ash or slagging mode. (Ash refers to the noncombustible mineral content of the feedstock, which, depending on the operating temperature of the gasifier, will be present either as a particulate- temperatures typically $<1100^{\circ} \mathrm{C}$ - or as a flowing slag-temperatures typically $>1300^{\circ} \mathrm{C}$. The operating temperature of a slagging gasifier is defined to a large degree by the melting point and viscosity of this residual ash.) The most significant materials reliability challenges are with slagging systems, where operating temperatures can range from $1350^{\circ} \mathrm{C}$ to $1600^{\circ} \mathrm{C}$ and materials of construction are exposed to both flowing slag and corrosive gases. Slagging gasifiers are typically lined with a refractory material, but in many designs, current-generation refractory materials do not provide sufficient service life to allow target system on-line availabilities (85-95\% for power generation) to be met (Figure 6). In addition, there is concern that the chromium oxide based refractory materials typically used might not be suitable for all potential gasifier feedstocks. Beyond refractories, there are also issues with corrosion and wear of feed injector systems and with excessive wear of com- 


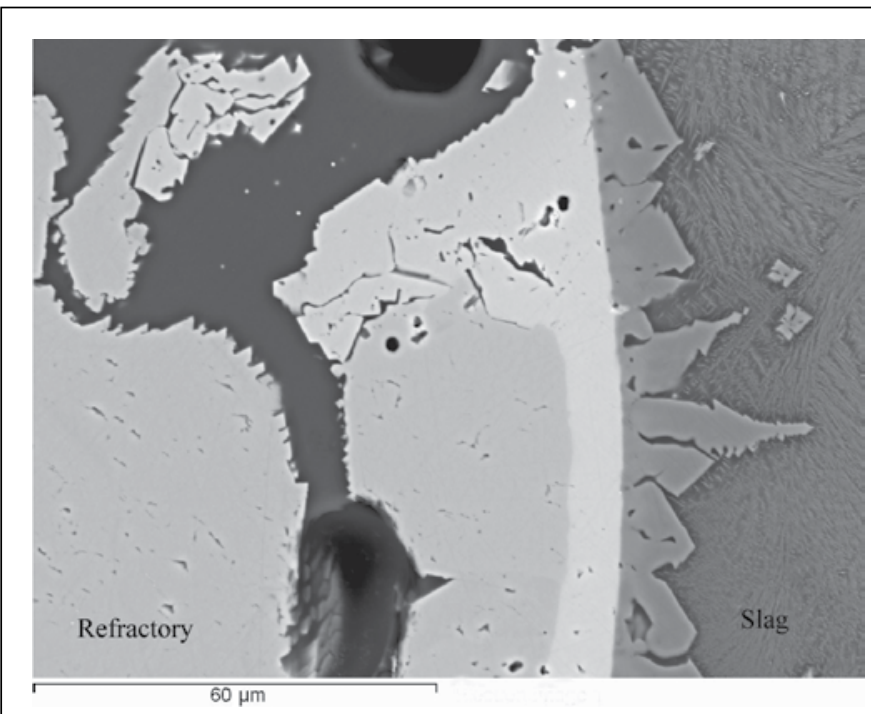

Figure 6. Refractory materials exposed to the operating environment inside a slagging coal gasifier must be designed to resist slag penetration and attack. Interaction with the slag at the hot face of this chromium oxide refractory results in a significant change in the refractory microstructure and ultimately loss of material. (Image courtesy of A. Petty and K. Collins of the National Energy Technology Laboratory.)

For oxygen-blown gasification, the requirement for a relatively inexpensive, reliable source of oxygen is the same as that described for oxy-fuel combustion. Advances in separation technologies and catalysis are also required in the post-gasifier conversion of synthesis gas to hydrogen and liquid fuels.

\section{Hydrogen from Coal}

Hydrogen can be produced from coal by first gasifying the coal to produce a cleaned synthesis gas and subjecting the gas to the water-gas shift reaction $\left(\mathrm{H}_{2} \mathrm{O}+\mathrm{CO} \leftrightarrow \mathrm{H}_{2}+\mathrm{CO}_{2}\right)$ in a catalytic reactor to increase the hydrogen content and convert the $\mathrm{CO}$ to $\mathrm{CO}_{2}$. The $\mathrm{CO}_{2}$ can then be separated for subsequent sequestration, leaving a relatively pure hydrogen stream to be used as a fuel in a hydrogen turbine or in a fuel cell. However, although this process is technically feasible today, issues with efficiency and cost still need to be addressed. ${ }^{8}$ From a materials standpoint, this means research to develop improved catalysts for the water-gas shift and membranes for hydrogen separation that are more tolerant of impurities such as sulfur, ammonia, and chlorides. Alternatively, $\mathrm{CO}_{2}$-selective membranes can be used to purify the hydrogen stream. Successful separation membranes will have a high flux at low pressure drops and operate at temperatures between $250^{\circ} \mathrm{C}$ and $500^{\circ} \mathrm{C}$. When the hydrogen from coal is intended for use in a fuel cell, membrane selectivity must ensure that carbon monoxide is present at concentrations of less than $10 \mathrm{ppm}$ and that sulfur-containing compounds are present at concentrations of less than $10 \mathrm{ppb}$. Successful transfer of membrane technology will require the development of effective high-temperature seals for membrane module assembly, as well as manufacturing methods that can reliably and affordably produce defect-free membranes. At a more fundamental level, a more complete understanding of membrane separation mechanisms will lead ultimately to the design of more effective separation systems.

Historically, hydrogen membranes (Figure 7) have been fabricated from various combinations of metals, ceramics, and

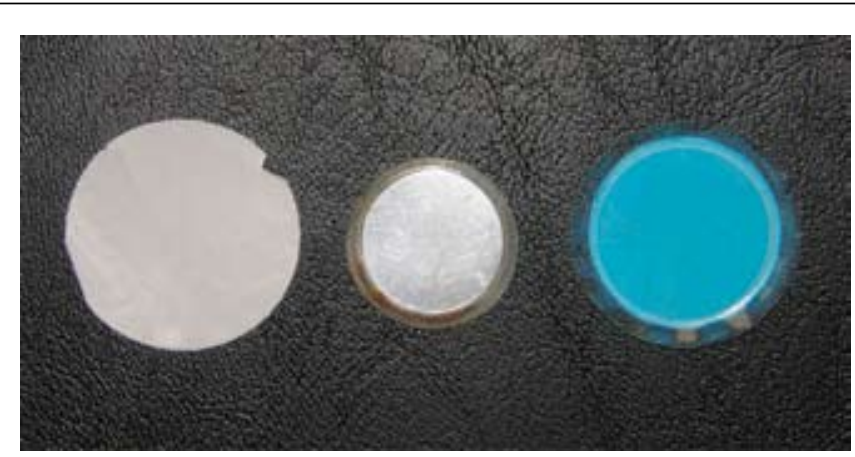

Figure 7. Hydrogen/ $/ \mathrm{CO}_{2}$ separation membranes currently under development: (left) Poly-ionic liquid membrane for $\mathrm{CO}_{2}$ removal; (center) multilayered, dense metal hydrogen separation membrane; and (right) copper-based, alumina-supported metal organic framework membrane for $\mathrm{CO}_{2}$ separation. (Image courtesy of D. Luebke, B. Howard, and M. Schwartz of the U.S. National Energy Technology Laboratory.)

polymers, with dense metal membranes yielding the highest selectivity and porous-based membranes providing the highest permeability. ${ }^{9}$ More recently, membranes composed of dense metal substrates coated with hydrogen-dissociation catalysts have shown relatively high permeability, selectivity, and mechanical strength in the laboratory, but have yet to be proved in the field. ${ }^{10}$ Carbon dioxide separation membranes (Figure 7), on the other hand, are typically based on polymers and depend on physical solubility to separate gases. The most advanced polymeric membranes today have selectivity values for $\mathrm{CO}_{2}$ to $\mathrm{H}_{2}$ of $\sim 10$. More recent research trends have focused on $\mathrm{CO}_{2}-$ selective membranes utilizing a facilitated transport mechanism such as ionic liquids and molten salts, which have shown the potential to increase performance under conditions associated with gasification. However, these chemically enhanced transport mechanisms suffer from instability and volatility of the transport media.

\section{Advanced Land-Based Combustion Turbines}

As with other components in advanced coal power plants, research continues into the development of next-generation stationary land-based combustion turbines that include both increased efficiency and reduced impact on the environment. These efforts are exemplified by DOE's FutureGen initiative, which aims to demonstrate a coal-fired IGCC power system that combines product flexibility and greater than $50 \%$ system efficiency with zero emissions by $2015 .{ }^{11}$ To accomplish this goal, turbines that are fuel flexible and capable of operating at temperatures in excess of $1400^{\circ} \mathrm{C}$ will be required. In the nearer term, these will be hydrogen turbines, capable of reliably burning fuel that contains a majority of hydrogen at high temperatures to maximize efficiency. In the longer term, it is expected that these will be oxy-fuel turbines, capable of combusting fuels consisting of nearly $100 \%$ hydrogen. ${ }^{12}$

From a materials standpoint, realization of the next generation of advanced turbines will require innovation in aerothermal concepts for cooling and heat-transfer management, combined with significant advances in materials technology. Traditionally, new materials and materials processes for landbased combustion turbines have been adapted from those developed for the aircraft engine industry, although not without significant challenges resulting from the much larger sizes of the stationary land-based turbines. This sharing of materials technology might continue in the future; however, 
the temperature requirements for land-based turbines and jet engines are merging, and the materials systems that can reliably and affordably withstand the DOE requirements for turbine technology have not yet been identified. In addition to high temperature, the hydrogen and oxy-fuel land-based turbines will operate with substantially higher moisture contents than current commercial turbines, placing additional requirements for environmental resistance on the materials of construction. For next-generation land-based hydrogen turbines, exhaust gases are expected to contain around $17 \% \mathrm{H}_{2} \mathrm{O}$, whereas oxy-fuel turbines are predicted to have exhaust gases composed of up to $90 \% \mathrm{H}_{2} \mathrm{O}$. This is in comparison to modern syngas turbines, where steam makes up less than $10 \%$ of the gas exhaust.

Within the hot section of the turbine, materials of construction will need to be resistant to oxidation, hot corrosion, creep, fatigue, and wear at temperatures in excess of $1400^{\circ} \mathrm{C}$ for long periods of operation $(30,000 \mathrm{~h}$ is the current target). Currentgeneration nickel- and cobalt-based superalloys cannot withstand sustained metal temperatures greater than approximately $1100^{\circ} \mathrm{C}$, requiring internal cooling as well as thermal-barrier and oxidation-resistant coatings to meet today's turbine performance requirements. As a result, it appears likely that the next generation of land-based turbines will require the development of new substrate materials, combined with new coating strategies, to meet the substantially higher temperature requirements. With sufficient internal cooling, silicides, nitrides, and refractory metal-based alloys all have potential to meet the temperature requirements presented by the next-generation turbine; however, each has significant issues with regard to environmental stability, especially in the presence of moisture, that will likely require mitigation through some form of protective coating strategy. In addition, the production and processing of these next-generation materials will be nontrivial, especially at the scale required for land-based turbine systems. In some cases, completely new processing strategies might need to be developed. Regardless, because of the need for long-term reliability in these components, defects introduced during processing will have to be kept to an absolute minimum. Computational methods that link various length and time scales to define a complete materials chemistry, microstructure, and processing strategy could be key to accelerating development of these next-generation materials.

In addition to the development of structural materials and improved coatings, sensors that can provide real-time turbine process information (temperature, pressure, gas composition) to the operator are needed to fully optimize system performance. These requirements are very similar to those necessary for gasifier systems. In addition, in situ sensors that can monitor component reliability and nondestructive methods for assessing component health during maintenance shutdowns are needed to maximize materials performance in this application.

\section{Coal to Liquid Fuels}

Utilizing the Fischer-Tropsch (FT) process, the synthesis gas produced by a coal gasifier can be condensed over a suitable metal catalyst to produce liquid fuels and/or chemical feedstocks. Transportation fuels produced by this methodology are sulfur-free, low in particulates, and low in nitrogen oxides. Although this is not a new process-South Africa has been producing coal-derived fuels since 1955 and currently produces more than $30 \%$ of that country's gasoline and diesel from indigenous coal-there is still room for improvement, particularly in the area of reaction chemistries. In FT synthesis, carbon monoxide is reacted with hydrogen in the presence of a solid metal catalyst, such as iron, cobalt, or ruthenium, to produce liquid hydrocarbons. Iron catalysts are most often employed for coal-derived syngas because iron has a higher water-gas shift activity and a significantly lower cost than cobalt. However, research is still needed to define the optimum catalyst size and shape for maximum activity and selectivity (Figure 8) and to improve catalyst stability and lifetime. ${ }^{13} \mathrm{~A}$ better understanding is also needed of catalyst behavior in the reactor environment, so that processes can be optimized for efficiency and yield. Computational studies, followed by experimental verification, will be key to identifying and optimizing promising reaction chemistries and chemical processing routes.

Liquid fuels, such as high-octane gasoline, can also be produced from coal by a direct liquefaction process called Bergius hydrocracking. However, because of its relatively high cost and poor environmental performance, this process is not currently commercialized.

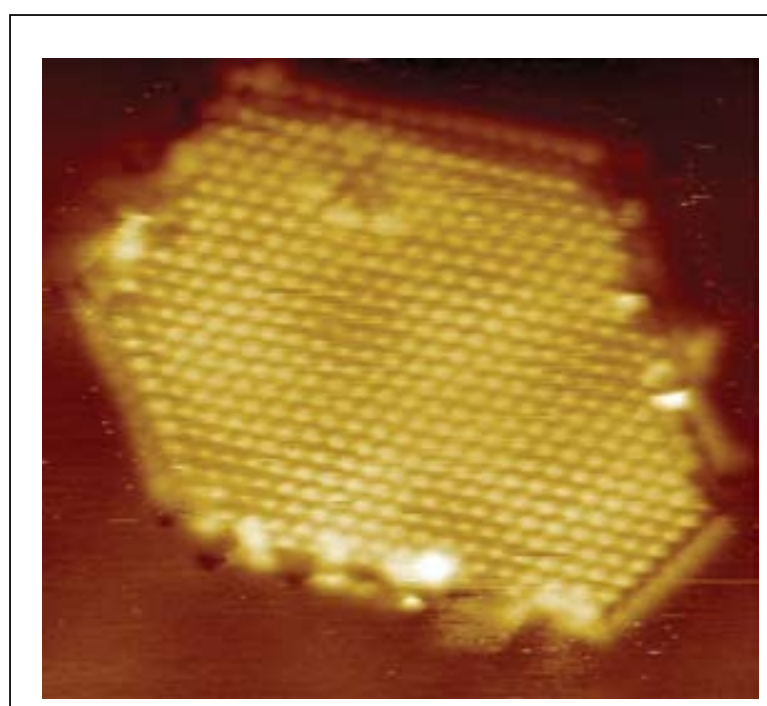

Figure 8. Catalyst size and shape optima are being explored to maximize reactivity in processes such as Fischer-Tropsch synthesis of liquid fuels from coal-derived synthesis gas, as illustrated in this $9 \mathrm{~nm} \times 10 \mathrm{~nm}$ scanning tunneling microscopy image of a single $\mathrm{FeO}$ particle grown on a $\mathrm{Au}(111)$ surface. (Image courtesy of N. Khan and C. Matranga of the National Energy Technology Laboratory.)

\section{Summary}

Coal will continue to be an important part of the world energy mix at least through the remainder of the 21 st century. Clean coal technologies are being developed that can make the conversion of coal to energy an efficient and environmentally benign process; however, their successful realization will require simultaneous advancements in materials science and technology. New materials that can reliably meet the demands of increased temperatures and pressures, and increasingly severe service environments while maintaining required performance characteristics are needed, as are advanced processing technologies that can economically produce components at the required scale. Computational methodologies that can accurately link the various scales of materials development, materials processing, and materials performance will help speed the time from concept development to component reality. 
References

1. The Coal Resource-A Comprehensive Overview of Coal (World Coal Institute, Richmond-upon-Thames, UK, 2005); www.worldcoal.org/assets $\mathrm{cm} /$ files/PDF/thecoalresource.pdf (accessed January 2008).

2. The Future of Coal-Options fora Carbon-Constrained World (Massachusetts Institute of Technology, Cambridge, MA, 2007); http://web.mit.edu/coal (accessed January 2008).

3. "Annual Energy Outlook 2007 With Projections to 2030" [Report DOE/EIA0383(2007), U.S. Department of Energy, Washington, DC, 2007]; http://tonto. eia.doe.gov/ftproot/forecasting/0383(2007).pdf (accessed January 2008). 4. R. Viswanathan, A.F. Armor, G. Booras, Power 148, 42 (2004).

5. "Fluidized Bed Technology-Overview" (Office of Fossil Energy, U.S Department of Energy, Washington, DC, 2007); www.fossil.energy.gov/ programs/powersystems/combustion/fluidizedbed_overview.html (accessed January 2008).

6. "What is Gasification?" (Gasification Technologies Council, Arlington, VA, 2007); www.gasification.org/Technology.htm (accessed January 2008).
7. N. Holt, Proceedings of the 2001 Gasification Technologies Conference (Gasification Technologies Council, Arlington, VA, 2007); www.gasification. org/Docs/2001_Papers/GTC01052.pdf (accessed January 2008).

8. "Hydrogen from Coal—Future Technologies" (Office of Fossil Energy, U.S Department of Energy, Washington, DC, 2007); www.fossil.energy.gov/ programs/fuels (accessed January 2008)

9. T.M. Nenoff, R.J. Spontak, C.M. Aberg, MRS Bull. 31 (10), 735 (2006).

10. M.V. Mundschau, X. Xie, C.R. Evenson, in Nonporous Inorganic Membranes, A.F. Sammells, M.V. Mundschau, Eds. (Wiley-VCH, New York, 2006), chap. 4.

11. J. Giove III, J. Daniels, V.K. Der, Power Ind. Dev. 12, 27 (2006).

12. The Turbines of Tomorrow (Office of Fossil Energy, U.S. Department of Energy, Washington, DC, 2007); www.fossil.energy.gov (accessed January 2008)

13. M. Jacoby, Chem. Eng. News 84, 57 (2006).

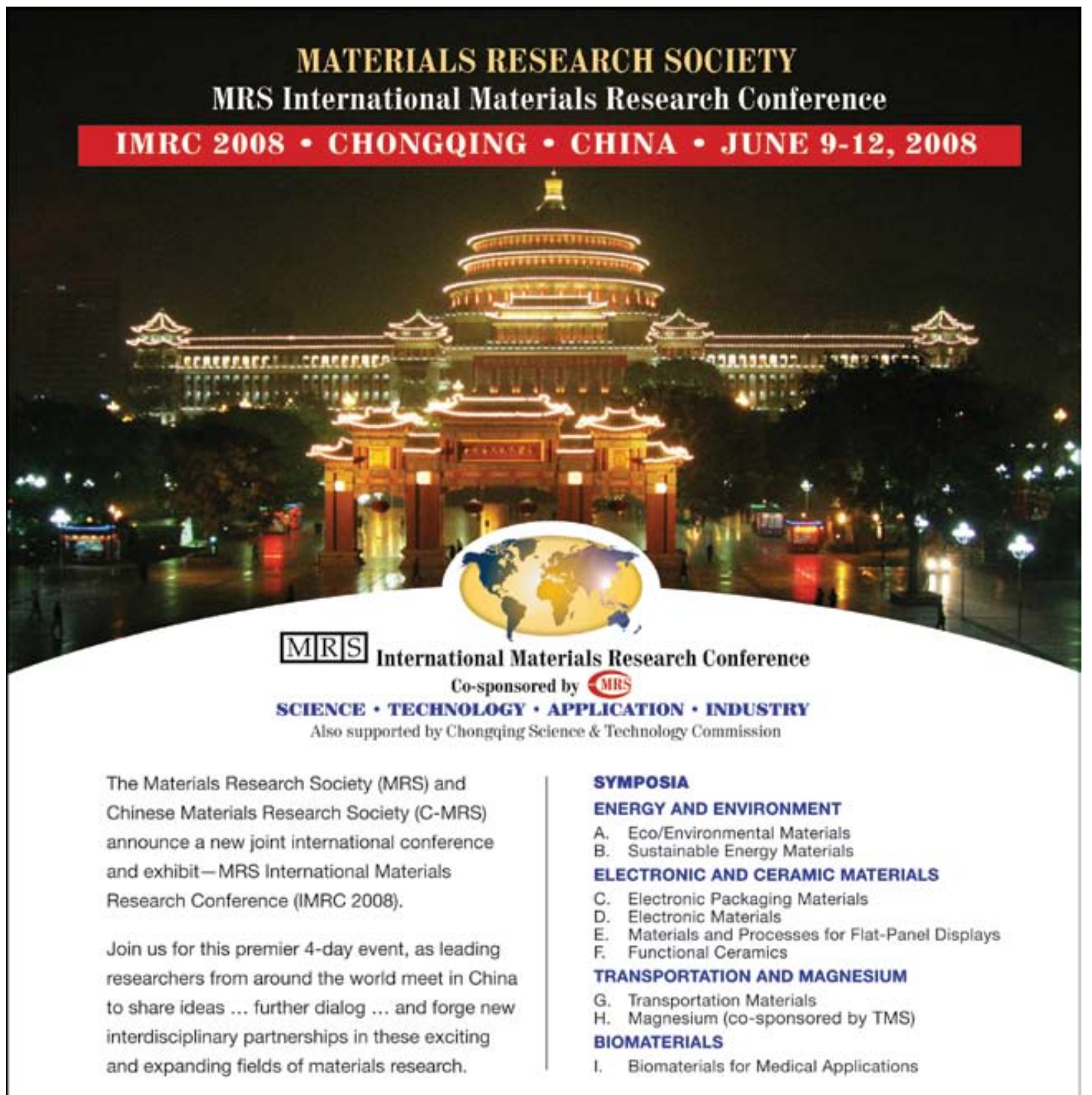




\section{Your Reference Source in NANOTECHNOLOGY}

\section{Handbook of}

THEORETICAL and COMPUTATIONAL NANOTECHNOLOGY

Edited by Michael Rieth and Wolfram Schommers, Germany

Foreword by Pierre-Gilles de Gennes, Nobel Prize Laureate

10-Volume Set

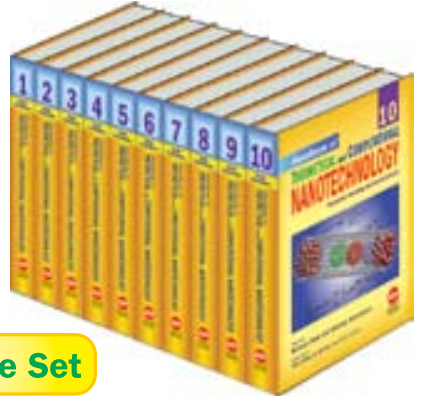

\section{6 / ca. 8,000 pages / Hardcover / ISBN: 1-58883-042-X / \$5,975.00 WWW. asplos. com/ten}

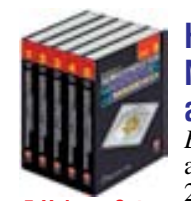

5-Volume Set

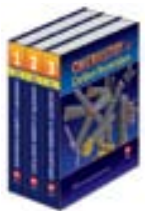

3-Volume Set

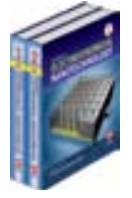

2-Volume Set
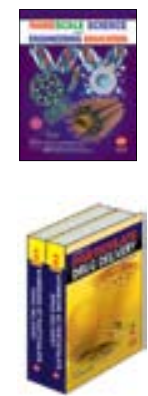

2-Volume Set
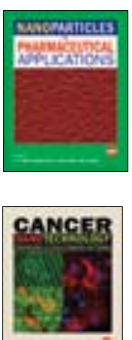
Edited by Hari Singh Nalwa, USA and Thomas Webster, USA 2007, 500 pages / Hardcove ISBN: 1-58883-071-3 / \$399.00

Chemistry of

Carbon Nanotubes

Edited by Vladimir A. Basiuk and Elena V. Basiuk, México ISBN: 1-58883-128-0 / \$998.00

Handbook of

Electrochemical

Nanotechnology

Edited by Yuehe Lin, USA

and Hari Singh Nalwa, USA

2008 / ca. 1500 pages / Harcove

\section{Nanoscale Science}

and Engineering Education

Edited by Aldrin E. Sweeney

and Sudipta Seal, USA

2008 / 712 pages / Hardcover

ISBN: 1-58883-085-3 / \$399.00

\section{Handbook of}

Particulate Drug Delivery

Edited by

M. N. V. Ravi Kumar, UK

2008 / 750 pages / Hardcover

ISBN: 1-58883-123-X / \$799.00

Nanoparticles for

Pharmaceutical Applications

Edited by A. J. Domb, Y. Tabata,

2007, ca. 500 pages / Hardcover

ISBN: 1-58883-089-6 / \$399.00

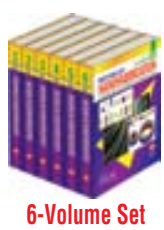

Bottom-up

Nanofabrication Supramolecules, Self-Assemblies, and Organized Films

Edited by Katsuhiko Ariga, Japan and Hari Singh Nalwa, USA 2008 / ca. 3000 pages / Hardcover 2006 / ca. 3,000 pages / Hardcover ISBN: 1-58883-073-X / \$1,999.00 2008 / ca. 1200 pages / Hardcover

M. N. V. Ravi Kumar, and S. Farber

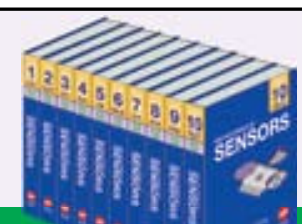

ENCYCLOPEDIA OF SENSORS

(Available in Print \& Online)

Edited by C. A. Grimes, E. C. Dickey, and M. V. Pishko

Foreword by Professor R. A. Marcus, Nobel Prize Laureate

2006, 6,000 pp, Hardcover, ISBN: 1-58883-056-X/\$6,999.00

Visit: www.asplbs.com

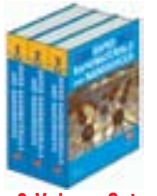

Doped Nanomaterials

and Nanodevices

Edited by Wei Chen, USA

( 1250 pages / Hardcover

ISBN: $1-58883-110-8$ / \$998.00

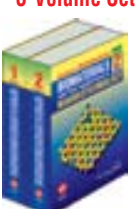

Handbook of Nanostructured Biomaterials and Their Applications in

Nanobiotechnology

Edited by Hari Singh Nalwa, USA 2005, ca. 1,000 pages / Hardcover

ISBN : 1-58883-033-0 / \$899.00

Polymer Nanocomposites

and Their Applications

Written by

Mosto Bousmina, Canada 1-58883-099-3 / \$399.00

Nanomaterials for Energy

Storage Applications

Edited by Hari Singh Nalwa, USA SBN: $1-58883-120-5 / \$ 399.00$

Emerging Technologies in Breast Imaging and Mammography Edited by Jasjit S. Suri,

and Swamy Laxminarayan, USA 2008 / 560 pages / Hardcover ISBN: 1-58883-090-X / \$399.00

\section{Nanotoxicology}

Edited by Yuliang Zhao, China and Hari Singh Nalwa, USA 2007 / 500 pages / Hardcover ISBN: 1-58883-088-8 / \$399.00
/ 600 pages / Hardcover

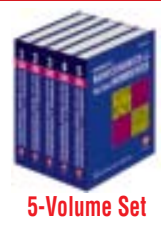

Handbook of

Nanoceramics and

Their Based Nanodevices

Edited by Tseung-Yuen Tseng, Taiwan and Hari Singh Nalwa, USA

2008 / ca. 4,000 pages / Hardcove ISBN: 1-58883-114-0 / \$2,999.00

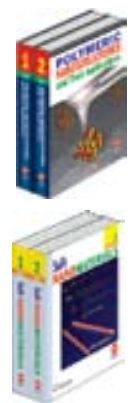

Polymeric Nanostructures and Their Applications Edited by

Hari Singh Nalwa, USA

2007 / 1142 pages / Hardcover

ISBN: 1-58883-068-3 / \$695.00

\section{Soft Nanomaterials}

Edited by

Hari Singh Nalwa, USA

2008 / ca. 800 pages / Hardcover

ISBN: 1-58883-040-3 / \$695.00

\section{2-Volume Set}

Packaging Nanotechnology Edited by Amar Mohanty, Manjusri Misra, and Hari Singh Nalwa, USA

2008 / ca. 350 pages / Hardcover

ISBN: 1-58883-105-1 / \$399.00

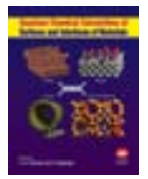

\section{Quantum Chemical}

Calculations of

Surfaces and Interfaces of Materials

Edited by Vladimir A. Basiuk, Mexico and Piero Ugliengo, Italy 2008 / ca. 600 pages / Hardcover ISBN: 1-58883-138-8 / \$399.00

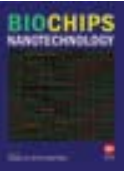

Biochips Nanotechnology Edited by Nongyue He, China and Hari Singh Nalwa, USA 2008 / ca. 500 pages / Hardcover ISBN: 1-58883-072-1 / \$399.00

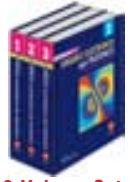

Handbook of Organic

Electronics and Photonics

Edited by Hari Singh Nalwa, USA

2008 / 1600 Pages / Hardcover ISBN: 1-58883-095-0 / \$998.00

3-Volume Set

\section{ORDER FROM}

\section{American Scientific Publishers}

25650 Lewis Way

Stevenson Ranch

California 91381-1439, USA

Tel.: 661-799-7200

Fax: 661-254-1207

E-mail: order@aspbs.com

Web: www.aspbs.com 